\author{
Mesut Alper GEZER, PhD \\ E-mail: alper.gezer@dpu.edu.tr \\ Department of Economics \\ Kütahya Dumlupınar University
}

\title{
THE IMPACT OF ECONOMIC FREEDOM ON HUMAN DEVELOPMENT IN EUROPEAN TRANSITION ECONOMIES
}

\begin{abstract}
Central and East European countries have experienced transformation from planned economies to market economies, and many had experienced EU integration at the similar periods. Both of these experiences increase the freedom of people, and institutions leaning on the new living conditions. This study asks the question whether increment in economic freedom brings an increment in development for Transition Economies in EU. Thereby, bivariate relationship between human development and economic freedom index is examined for 11 Transition Economies for the period of 1996-2018. Firstly, bivariate cointegration relationship is assessed considering cross section dependency situation. CCE, AMG, and fixed effect estimators are preferred due to the fact to take cross section dependency into consideration. Secondly, bivariate bootstrap Granger causality relationship has been investigated to search the direction of relationship in the short run. Meanwhile, bivariate bootstrap causality relationship between human development and sub-indices of economic freedom has been examined to clarify nexus in deep. It can be stated that economic freedom has an effect on development both in short and long run for the selected period.

Keywords: Economic Freedom, Human Development, Transition, Granger Causality, Cross Section Dependency.
\end{abstract}

JEL Classification: C23, C5, I31, O11, P26

\section{Introduction}

Smith (1776) states that the effort of every individual to make them better off creates a strong effect on society in promoting welfare and wealth without any guidance, when integrated with freedom and security. One of the difficulties related with this issue is the measurement of the welfare and wealth in reflecting real dynamics and effects for its development. Most studies use per capita GDP indicator as a representative of growth, wealth, welfare, or development of countries as like (De Haan and Siermann, 1998; Farr et al., 1998; Heckelman, 2000; Dawson, 2003; Piatek et al., 2013; Panahi et al., 2014; Acikgoz et al., 2016) for the impact of economic freedom on development. HDI brings an alternative

DOI: $10.24818 / 18423264 / 54.3 .20 .10$ 
yardstick for development that evaluates the degree and promotion of development concept much broader than income. HDI comprises of three main indices, which are life expectancy, education and GNI. These three indices take health, knowledge and standard of living situation of countries into consideration, respectively (UNDP, 2010). Sen (1993) exemplifies two hypothetical countries, which one of them has more per capita GDP, and other has more life expectancy. So, the quality of life does not only base on per capita income level. Country, who has more life expectancy, means more health services for poor people, and more access to education. GDP can veil misery and poverty, and it is an inadequate indicator of development relative to HDI (Goldsmith, 1997).

Economic freedom is decided as one of the important stimulator of development of a country, and its impact on well-being. One of the fundamental roles of government is to guarantee and monitor property rights and implementation of contracts. If governments fail to ensure private property, and protect people's properties without any compensation, or institutional regulations restrict trade, undermine property rights, then people lose their incentive to get in productive activities (De Haan and Siermann, 1998). This is in line with Esposito and Zaleski (1999) that greater the influence of government on resource allocation, resources would be wandered away productive activities. Trustworthy property rights and low taxes create more incentive towards productive activities, and the increment in freedom encourages competition, and allocates resource more efficiently (Gwartney et al., 1999). So, it can be stated that private property and rule of law are the fundamentals of economic freedom, which encourage specialization and efficient resource allocation by rising freedom of exchange and lowering transaction cost of security of property rights (Esposito and Zaleski, 1999). One of the other difficulties is the indication of economic freedom. I use economic freedom index of the Heritage Foundation, which is the weighted average of four main indices as rule of law, government size, regulatory efficiency, and market openness at this study.

Transition economies have exercised a radical transformation from autocracy to democracy and from planned economy to market economies in 1990s. At the same time, 11 transition economies have joined to European Union on different dates. It can be interpret that these countries have experienced both transformation and integration at the same time. However, it is also observed that welfare level is higher in transition economies, which have high level of political and economic freedom (Piatek et al., 2013). The organisation of paper follows that literature review takes place at the second part for the bivariate relationship between HDI and economic freedom. Model and data is expressed at the third part, and cross sectional dependency situation of 11 transition economies is taken into consideration for further estimations. Cointegration relationship is discussed leaning on cross section dependency. CCE, AMG, and Driscoll and Kraay (1998) panel fixed effect estimators are used based on unit root, co-integration and spatial 
The Impact of Economic Freedom on Human Development in European Transition Economies

dependency situation. Furthermore, bootstrap panel causality method is used to express causal relationship both in whole panel and cross sections, respectively.

\section{Literature Review}

Piatek et al. (2013) examine the causal relationship among economic freedom, political freedom and economic growth according to Wald test in 25 transition economies spanned from the period of 1990-2008. Empirical findings suggest that economic freedom has a positive and significant contribution to economic growth on average both in transition and developed countries. Ram (2014) investigates the effect of economic freedom on human development index for 142 countries based on a parsimonious specification. Economic freedom index is verified with Heritage and Frasier indices, and human development index is split in half as income and non-income based HDI. Empirical findings reveal that there is significant and positive impact of economic freedom on income and non-income based HDI just in Fraser economic freedom index models. A similar approach is held by Guney (2017), who evaluates the impact of economic freedom index and sub-indices on human development index for OECD countries for the period of 1990-2014 in terms of system GMM model. Empirical results indicate that all subindices have a positive and significant contribution on human development index. Meanwhile, Bahtiyar and Karabacak (2018) assess the same relationship from the aspect of bootstrapped panel causality model for G7 and E7 countries leaning on Konya (2006) methodology for the period of 1995-2015.

According to Goldsmith (1997), economic rights and national income move together. Government regulations in property and contracts towards economic rights stimulate rapid material progress. Goldsmith (1997) investigates bivariate cross section regression between two based on three different economic freedom indices, separately. Empirical findings suggest that Heritage Foundation index model reflect negative significant impact on human development, whereas others have positive and significant impact. Farr et al. (1998) examine Granger causal nexus among political freedom, economic freedom and well-being for 100 countries for the period of 1975-1995. Well-being is represented with real per capita GDP. They found bi-directional causal relationship between economic freedom and well-being with a feedback effect.

Graafland (2019) uses generalised trust as a moderator between economic freedom and human development for 29 OECD countries. Countries, which have high level of trust but less economic freedom, can increase their performance by concentrating quality of property rights. Acikgoz et al. (2016) search the nexus between fiscal, and business freedom and growth based on a cointegration relationship for the period of 1993-2011. They group 107 countries into three group based on freedom level. They emphasize that fiscal freedom as tax burden give a positive and significant efficacy to growth whereas business freedom creates same impact for only two country group. This idea has been extended by Gwartney

DOI: $10.24818 / 18423264 / 54.3 .20 .10$ 
et al. (1999), who argue that the existence of reverse causality between growth and economic freedom. The fact that more freedom causes more growth can also create more freedom in more free countries in the future. Heckelman (2000) discusses reciprocal Granger causal relationship between economic growth and sub-indices of Heritage economic freedom index. Direction of causality from freedom to growth is more dominant than reverse direction for 94 countries for the period of 1994-1997.

\section{Data and Methodology}

Dataset covers the period of 1996-2018 for 11 Transition European economies. While data of economic freedom (EFI) is taken from The Heritage Foundation (2019), data of human development index (HDI) is taken from UNDP (2019). Whole dataset is prepared in a balanced panel sense, so 1996 is chosen as the beginning date for the period to include more countries instead of 1995. First of all, unit root structure of the data becomes the subject to interrogate. If there is unit root in an econometric series for instance $y_{t}=\rho y_{t-1}+\varepsilon_{t}$, it makes economic shock continuous for a random walk process when $\rho=1$ (Wooldridge, 2013). But, cross section dependency and homogeneity situation of panel becomes important before unit root investigation. If cross section dependence is neglected in data, biased and size distorted estimations will be in case (Pesaran, 2006).

Table 1.Descriptive Statistics

\begin{tabular}{|c|c|c|c|c|}
\hline Variables & Mean & Std. Dev. & Maximum & Minimum \\
\hline HDI & 0.80 & 0.05 & 0.90 & 0.68 \\
\hline EFI & 64.01 & 7.36 & 79.10 & 45.70 \\
\hline -PR & 55.06 & 15.47 & 90.00 & 30.00 \\
\hline -GI & 46.13 & 10.66 & 75.70 & 26.00 \\
\hline -TB & 73.42 & 11.77 & 94.00 & 42.40 \\
\hline -GS & 46.73 & 15.46 & 79.70 & 0.00 \\
\hline -BF & 70.73 & 9.44 & 100.00 & 53.70 \\
\hline -MF & 73.30 & 16.11 & 91.70 & 0.00 \\
\hline -TF & 80.05 & 9.68 & 88.00 & 46.80 \\
\hline
\end{tabular}

Note: - reflects sub-indices of economic freedom index. PR: Property Rights, GR: Government Integrity, TB: Tax Burden, GS: Government Spending, BF: Business Freedom, MF: Monetary Freedom, TF: Trade Freedom.

Summary statistics of variables are expressed in Table 1.7 sub-indices of economic freedom index out of 12 are considered, 3 of them are neglected due to lack of data, which are judicial effectiveness, fiscal health, and labour freedom; and investment freedom and financial freedom are excluded due to near singular matrix 
The Impact of Economic Freedom on Human Development in European Transition Economies

problem in bootstrap causality analysis. The correlation between HDI and EFI is 0.62 .

$C D_{L M 1}=T \sum_{i=1}^{N} \sum_{j=1}^{N-1} \rho_{i j}^{2}$

Breush and Pagan (1980) create a test procedure for cross section dependency based on Lagrange Multiplier. $\rho_{i j}^{2}$ is the estimate of the cross sectional correlation among residuals. Cross sectional dependence is tested for the null hypothesis of $H_{0}: \operatorname{Cov}\left(\varepsilon_{i t}, \varepsilon_{j t}\right)=0$ for $i=j$, against the alternative hypothesis of $H_{A}: \operatorname{Cov}\left(\varepsilon_{i t}, \varepsilon_{j t}\right) \neq 0$ for at least one couple of $i \neq j$ with a fixed $N$ and $T \rightarrow \infty$ under $\chi^{2}$ distribution based on $(N x(N-1) / 2)$ degrees of freedom (Guloglu and Ivrendi, 2008).

$C D_{L M 2}=\sqrt{\frac{1}{N(N-1)}} \sum_{i=1}^{N-1} \sum_{j=i+1}^{N}\left(T \rho_{i j}^{2}-1\right) ; C D=\sqrt{\frac{2 T}{N(N-1)}} \sum_{i=1}^{N-1} \sum_{j=i+1}^{N} \rho_{i j}$

Pesaran (2004) proposes a valid cross section dependency $C D_{L M 2}$ testing for size distortion, where $N \rightarrow \infty$ and $T \rightarrow \infty$. In accordance with this, he also develops a $C D$ test for large $N$ and small $T$ situation for asymptotically standard normal distribution (Kar et al., 2011).

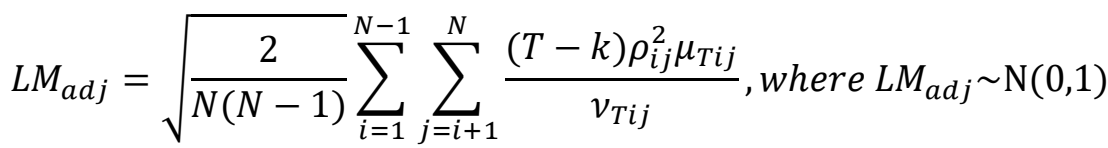

Pesaran et al. (2008) introduce a modified $L M$ test for $N \rightarrow \infty$ and $T \rightarrow \infty$ due to the lack power situation of $C D$ test, where mean pairwise correlations are zero (Menyah et al., 2014).

$\tilde{\Delta}=\sqrt{N}\left(\frac{N^{-1} \tilde{S}-k}{\sqrt{2 k}}\right) ; \quad \tilde{\Delta}_{a d j}=\sqrt{N}\left(\frac{N^{-1} \tilde{S}-E\left(\tilde{Z}_{i t}\right)}{\sqrt{\operatorname{var}\left(\tilde{Z}_{i t}\right)}}\right)$

Pesaran and Yamagata (2008) develop two testing, which are delta and delta-adjusted for the homogeneity of panel, whereas adjusted version is more appropriate for small samples. $H_{0}: \beta_{i}=\beta_{j}$ is the null hypothesis of homogeneity against the alternative hypothesis of $H_{A}: \beta_{i} \neq \beta_{j}$.

DOI: 10.24818/18423264/54.3.20.10 


\subsection{Unit Root and Co-integration Methodology}

One of the panel unit root test at the existence of cross section dependency is developed by Pesaran (2007), which take cross dependence of the series into consideration before standard unit root test procedure. This test enlarges the standard unit root procedure of $\mathrm{ADF}$ regressions with means of cross sections lagged levels and first differences of each cross section.

$\Delta y_{i t}=\alpha_{i}+\beta_{i} y_{i, t-1}+c_{i} \bar{y}_{i, t-1}+d_{i} \Delta \bar{y}_{i}+\varepsilon_{i t} ;$ for $i=1,2, \ldots, N ; t=1,2, \ldots, T$

Cross section augmented regression model is expressed in equation 5, where $\bar{y}_{i}$ is the cross section averages of each individual units.

$t_{i}(N, T)=\frac{\Delta y_{i}^{\prime} \bar{M}_{w} y_{i,-1}}{\hat{\sigma}_{i}\left(y_{i-1}^{\prime} \bar{M}_{w} y_{i,-1}\right)^{1 / 2}}$

$\mathrm{t}$ ratio takes place in equation 6 , where $\Delta y_{i}=\left(\Delta y_{i 1}, \ldots, \Delta y_{i T}\right)^{\prime}, \quad y_{i,-1}=$ $\left(y_{i 0}, \ldots, y_{i, T-1}\right)^{\prime}, \bar{M}_{w}=I_{T}-\bar{W}\left(\bar{W}^{\prime} \bar{W}\right)^{-1} \bar{W}^{\prime}$, and $\hat{\sigma}_{i}^{2}=\frac{\Delta y_{i}^{\prime} M_{i, w} \Delta y_{i}}{T-4}$. The null hypothesis of each cross section is $H_{0}^{i}: \beta_{i}=0$, against the alternative hypothesis of $H_{0}^{i}: \beta_{i}<0$ for the second generation panel unit root. Besides, CIPS statistics is also introduced for the extreme values of each individual based on averages of each cross section as CIPS $=N^{-1} \sum_{i=1}^{N} C A D F_{i}$ for $N$ and $T$ tending to infinity.

Bai and $\mathrm{Ng}$ (2004) introduce PANIC test to clarify whether nonstationarity of a series stem from idiosyncratic part or common factor, or both of them in a second generation panel sense. Common factor based model is displayed in equation 7, where $D_{i t}$ is polynomial trend function, $F_{t}$ is the common factor vector, $X_{i t}$ is the deterministic component, and $e_{i t}$ is the idiosyncratic error term.

$X_{i t}=D_{i t}+\lambda_{i}^{\prime} F_{t}+e_{i t}$

If the $F_{t}$ common factor is stationary in the model, which comes from principal component, than $e_{i t}$ idiosyncratic error term is the source of the unit root. In accordance with this, they implement principal component to the first differenced equation of the model, and estimate loadings and common factors of each models by applying ADF regressions. They tested unit root for pooled model and group separately related with the homogeneity situation of the panel in terms of non-stationarity of null hypothesis.

Westerlund (2008) introduces Durbin-Hausman test for co-integration relationship in cross sectionally dependent series by using common factors. Common factor is determined according to principal components. 
The Impact of Economic Freedom on Human Development in European Transition Economies

$D H_{g}=\sum_{i=1}^{n} \hat{S}_{i}\left(\widetilde{\emptyset}_{i}-\widehat{\emptyset}_{i}\right)^{2} \sum_{t=2}^{T} \hat{e}_{i t-1}^{2}$ and $D H_{p}=\sum_{i=1}^{n} \hat{S}_{n}\left(\widetilde{\emptyset}_{i}-\widehat{\emptyset}_{i}\right)^{2} \sum_{i=1}^{n} \sum_{t=2}^{T} \hat{e}_{i t-1}^{2}$

Durbin-Hausman test statistics take place in equation 8, as pooled and group separately. While pooled statistics assumes homogeneity of panel, group statistics bases on heterogeneity. Null hypothesis leans on non-existence of cointegration as $H_{0}: \emptyset_{i}=1$ for all $i=1, \ldots, n$ against alternative hypothesis of cointegration $H_{A}: \emptyset_{i}<1$ and $H_{A}: \emptyset_{i}=\varnothing$ for all $i$ in pooled statistics. On the other hand, $H_{0}: \emptyset_{i}=1$ is tested against $H_{A}: \emptyset_{i}<1$ in group statistics for at least some $i$. So rejection of null does not mean that all units are cointegrated in group statistics, but only for some. $\hat{S}_{i}=\widehat{w}_{i}^{2} / \widehat{\sigma}_{i}^{4}, \hat{S}_{n}=\widehat{w}_{n}^{2} /\left(\hat{\sigma}_{n}^{2}\right)^{2}$, where $\widehat{w}_{i}^{2}$ is the Kernel estimator. $\Delta z_{i t}=\lambda_{i}^{\prime} \Delta F_{t}+\Delta e_{i t}, F_{t}$ is the vector of common factors, and $\hat{e}_{i t}=\emptyset \hat{e}_{i t-1}+\varepsilon_{i t}$.

\subsection{Estimators Methodology}

Eberhardt and Bond (2009) put into forward two steps AMG method, which make consistent estimation for heterogeneous data under cross section correlation, including variable and factor non-stationarity.

$y_{i t}=\beta_{i}^{\prime} x_{i t}+u_{i t}, u_{i t}=\alpha_{i}+\lambda_{i}^{\prime} f_{t}+\varepsilon_{i t}$

$x_{m i t}=\delta_{m i}^{\prime} g_{m t}+\rho_{1 m i} f_{1 m t}+\cdots+\rho_{n m i} f_{n m t}+v_{m i t} ; m=1, \ldots, k$

$f_{t}=\varrho^{\prime} f_{t-1}+\epsilon_{t}$ and $g_{t}=\kappa^{\prime} g_{t-1}+\epsilon_{t}$

Models are expressed in equations 9-11, $x_{i t}$ is a vector of observable covariables, $\alpha_{i}$ is group specific fixed effect, $\beta_{i}$ are unknown random coefficients, $\lambda_{i}$ is country specific factor loadings, $f_{t}$ is a set of common factors, $f_{t}$ and $g_{t}$ are unobserved common factors' linear functions, and $f_{m t}$ are subsets of $f_{t}$.

$\Delta y_{i t}=b^{\prime} \Delta x_{i t}+\sum_{t=2}^{T} c_{t} \Delta D_{t}+e_{i t} ; \rightarrow \hat{c}_{t} \equiv \hat{u}_{t}^{\bullet} ; \quad$ Stage (1)

$y_{i t}=\alpha_{i}+b_{i}^{\prime} x_{i t}+c_{i} t+d_{i} \hat{u}_{t}^{\bullet}+e_{i t} ;$

Stage (2)

AMG estimator in two-stages is expressed in equation 12 and 13, where $\hat{u}_{t}^{*}$ are year dummy variables. In first stage, first difference regressions are taken into considerations to avoid bias estimates of nonstationary variables and unobservables. At second stage linear trend terms are added to reflect omitted idiosyncratic procedures. AMG estimators are attained according to means of individual country estimates, $\hat{b}_{A M G}=N^{-1} \sum_{i} \hat{b}_{i}$.

DOI: $10.24818 / 18423264 / 54.3 .20 .10$ 
Pesaran (2006) suggests consistent and asymptotically normal coefficients estimates even in the case of correlations of unobserved common effects as well. He posits a multifactor residual model, and differentiates between individual specific effects and observed and unobserved common effects by introducing CCE estimator. The main idea of estimation process is to filtrates individual specific regressors by aggregates of cross section averages in a way of excluding unobserved common factor differential effects. It is seen that CCE is asymptotically unbiased estimator without any convergence restriction on $N$ and $T$.

$$
\begin{aligned}
& y_{i t}=\alpha_{i}^{\prime} d_{t}+\beta_{i}^{\prime} x_{i t}+e_{i t} ; \quad e_{i t}=\gamma_{i}^{\prime} f_{t}+\varepsilon_{i t} \\
& x_{i t}=A_{i}^{\prime} d_{t}+\Gamma_{i}^{\prime} f_{t}+v_{i t}
\end{aligned}
$$

Models of CCE estimation are expressed in equation 14 and 15, where $d_{t}$ is a vector of observed common effects, $x_{i t}$ is a vector of observed individual specific regressors, $f_{t}$ is the vector of unobserved common effects, $\varepsilon_{i t}$ is idiosyncratic errors, $A_{i}$ and $\Gamma_{i}$ are loading factor matrices. Deterministic trends and non-stationary roots are evaluated in $x_{i t}$ and $y_{i t}$ by letting at least one common effect in $d_{t}$ and $f_{t}$, which have unit roots and/or deterministic trends.

$\widehat{b}_{i}=\left(X_{i}^{\prime} \bar{M}_{w} X_{i}\right)^{-1} X_{i}^{\prime} \bar{M}_{w} y_{i}$

Individual slope coefficients of $\mathrm{CCE}$ is demonstrated in equation 16, where $\bar{M}_{w}=I_{T}-\bar{H}_{w}\left(\bar{H}_{w}^{\prime} \bar{H}_{w}\right)^{-1} \bar{H}_{w}^{\prime}, \bar{H}_{w}=\left(D, \bar{Z}_{w}\right)$ and $D$ and $\bar{Z}_{w}$ are matrices of observations on $d_{t}$ and $\bar{z}_{w t}$. This estimator has been extended with CCEMG, which is a simple mean of individual estimators, $\hat{b}_{M G}=N^{-1} \sum_{i=1}^{N} \hat{b}_{i}$.

According to Driscoll and Kraay (1998) existence of cross section dependency causes inconsistent standard error estimates of coefficients. They propose a nonparametric correction for spatial dependence, which is similar to the nonparametric serial dependence of time series correction.

$\hat{\theta}_{T}=\underset{\{\theta\}}{\operatorname{argmin}}\left\lceil\frac{1}{T} \sum_{t=1}^{T} \tilde{h}_{t}(\theta)\right\rceil^{\prime} \hat{S}_{T}^{-1}\left\lceil\frac{1}{T} \sum_{t=1}^{T} \tilde{h}_{t}(\theta)\right\rceil$

They use GMM covariance matrix estimator by hoarding $R$ orthogonality condition for each $N$, and $\theta$ is the parameter vector of this estimator. $\tilde{S}_{T}$ is a consistent estimator of $N R x N R$ matrix, required for the variance estimation of GMM. So, non-parametric covariance matrix estimation causes robust standard error estimation against spatial dependence when $T$ is larger than $N$ dimension. 
The Impact of Economic Freedom on Human Development in European Transition Economies

\subsection{Panel Causality Methodology}

Konya (2006) suggests bootstrap SUR panel simultaneous equation model to examine bivariate Granger causality relationship. This procedure has some advantages compared with other panel causality approaches. This process does not require pretesting of unit root and co-integration investigation due to bootstrap method's extra information for panel dataset. It also reckons with cross section dependency, and the direction of causality is specified by Wald test with individual specific bootstrap critical values. The only imperative condition is to determine lag length before analysis. SUR models create better coefficient estimation than OLS models if simultaneous correlation exists in the system. Wald tests are applied to each individual and bootstrap statistics are obtained with ten thousands replicates.

$$
\begin{aligned}
& h d i_{1, t}=\alpha_{1,1}+\sum_{l=1}^{\text {lhdi1 }} \beta_{1,1, l} h d i_{1, t-1}+\sum_{l=1}^{\text {lefi } 1} \theta_{1,1, l} \text { ef } f_{i 1, t-1}+\varepsilon_{1,1, t} \\
& h d i_{2, t}=\alpha_{1,2}+\sum_{l=1}^{l h d i 1} \beta_{1,2, l} h d i_{2, t-1}+\sum_{l=1}^{l e f i 1} \theta_{1,2, l} \text { ef } i_{2, t-1}+\varepsilon_{1,2, t} \\
& \vdots \\
& h d i_{N, t}=\alpha_{1, N}+\sum_{l=1}^{l h d i 1} \beta_{1, N, l} h d i_{N, t-1}+\sum_{l=1}^{l e f i 1} \theta_{1, N, l} \text { efi } i_{N, t-1}+\varepsilon_{1, N, t}
\end{aligned}
$$

and

$$
\begin{aligned}
& \text { ef } i_{1, t}=\alpha_{2,1}+\sum_{l=1}^{\text {lhdi } 2} \beta_{2,1, l} h d i_{1, t-1}+\sum_{l=1}^{\text {lefi } 2} \theta_{2,1, l} \text { efi } i_{1, t-1}+\varepsilon_{2,1, t} \\
& \text { ef } i_{2, t}=\alpha_{2,2}+\sum_{l=1}^{\text {lhdi2 }} \beta_{2,2, l} h d i_{2, t-1}+\sum_{l=1}^{l e f i 2} \theta_{2,2, l} \text { efi } i_{2, t-1}+\varepsilon_{2,2, t} \\
& \vdots \\
& \text { ef } i_{N, t}=\alpha_{2, N}+\sum_{l=1}^{l h d i 2} \beta_{2, N, l} h d i_{N, t-1}+\sum_{l=1}^{l e f i 2} \theta_{2, N, l} \text { efi } i_{N, t-1}+\varepsilon_{2, N, t}
\end{aligned}
$$

SUR model contemporaneous system dynamics are expressed in equations 18 and 19. $l$ is the predetermined lag length of the system, $N$ and $T$ are individual and time dimension respectively, and $\varepsilon_{1,1, t}$ and $\varepsilon_{2,1, t}$ are white noises and

DOI: 10.24818/18423264/54.3.20.10 
correlated for each cross sections. 1-4 lags are pre-assumed, and Schwartz information $\left(S C_{k}=\ln |W|+\frac{N^{2} q}{T} \ln (T)\right)$ is predetermined before analysis. There is unidirectional Granger causality running from EFI to HDI if in equation 18 not all $\theta_{1, i}$ 's are zero, but all $\beta_{2, i}$ 's are zero in equation 19. Moreover, there is unidirectional causality running from HDI to EFI if all $\theta_{1, i}$ 's are zero in equation 18 , but not all $\beta_{2, i}$ 's are zero in equation 19 . Finally, there is bidirectional causality between EFI and HDI if neither all $\beta_{2, i}$ 's nor all $\theta_{1, i}$ 's are zero, there is no Granger causality between EFI and HDI, if all $\beta_{2, i}$ 's and $\theta_{1, i}$ 's are zero.

\section{Empirical Findings}

First of all, cross section contemporaneous correlation of each variable is discussed at Table 2 .

Table 2.Findings of Cross Section Dependency

\begin{tabular}{|c|c|c|}
\hline Tests & HDI & EFI \\
\hline LM1 & $123.197 * * *$ & $98.119 * * *$ \\
\hline LM2 & $6.502 * * *$ & $4.111^{* * *}$ \\
\hline CD & $-1.773 * * *$ & $-2.166 * * *$ \\
\hline LM $_{\text {adj }}$ & $6.869 * * *$ & $2.387 * * *$ \\
\hline
\end{tabular}

Note: $* * *$ indicates significance at 0.01 levels. 4 lag is determined for each evaluation. All calculations are done with Gauss 10.

It is seen that all variables has a trend in their series. So, all variables are tested under constant and trend assumption.

Table 3.Findings of Unit Root under Cross Section Dependency

\begin{tabular}{|c|c|c|}
\hline \multicolumn{3}{|c|}{ Level } \\
\hline Tests & HDI & EFI \\
\hline CIPS-stat & 2.668 & 2.105 \\
\hline PANIC-Choi & -1.009 & 1.083 \\
\hline PANIC-Mw & 15.304 & 29.181 \\
\hline \multicolumn{3}{|c|}{ First Difference } \\
\hline CIPS-stat & $-2.948^{* *}$ & $2.750^{*}$ \\
\hline PANIC-Choi & $2.981^{* * *}$ & $3.762^{* * *}$ \\
\hline PANIC-Mw & $41.776^{* * *}$ & $46.958^{* * *}$ \\
\hline
\end{tabular}

Note: $*, * *, * * *$ indicate significance at the $0.1,0.05$, and 0.01 levels, respectively. 4 lag is determined for each evaluation. All calculations are done with Gauss 10, and based on constant and trend together. 
The Impact of Economic Freedom on Human Development in European Transition Economies

Unit root findings are taken place in Table 3 according to Pesaran (2007) CADF test and Bai and $\mathrm{Ng}$ (2004) PANIC test. All variables have unit root at their level, and they get rid of from unit root in their first differences. So, variables are appropriate for cointegration investigation.

$$
\begin{array}{ll}
H D I_{i, t}=\alpha_{1}+\beta_{1} E F I_{i, t}+\theta_{1} t+\varepsilon_{i, t} ; & \text { Model } 1 \\
E F I_{i, t}=\alpha_{2}+\beta_{2} H D I_{i, t}+\theta_{2} t+\varepsilon_{i, t} ; & \text { Model } 2
\end{array}
$$

Models for cointegration relationship and estimator's models are demonstrated in equation 20 and 21. Model 1 and Model 2 reflect bivariate reciprocal relationship between HDI and EFI.

Table 3.Cointegration and Homogeneity Findings

\begin{tabular}{|c|c|c|}
\hline Tests & Model 1 & Model 2 \\
\hline DH-panel & -0.502 & -0.744 \\
\hline DH-group & $-1.460^{*}$ & $-1.853^{* *}$ \\
\hline Delta & $4.233^{* * *}$ & $12.894 * * *$ \\
\hline Delta-adjusted & $4.525^{* * *}$ & $13.784 * * *$ \\
\hline
\end{tabular}

Note: $*, * *, * * *$ indicate significance at the $0.1,0.05$, and 0.01 levels, respectively. 4 lag length and maximum common factor are determined for each evaluation under constant and trend. All calculations are done with Gauss 10.

While DH-panel deals with cointegration relationship under homogeneous pooled panel assumption, DH-group considers heterogeneity in panel data according to Westerlund (2008). Delta and Delta-adjusted examine homogeneity leaning on Pesaran and Yamagata (2008); in respect to this both of them reject homogeneity. Thus, DH-group findings are more proper for this panel structure, which reflect significant cointegration relationship in both models.

Table 4.Estimation Findings of Fixed Effect

\begin{tabular}{|c|c|}
\hline Variables & Model 1 \\
\hline Economic Freedom & $0.00114(0.00028)^{* * *}$ \\
\hline Trend & $0.00515(0.00042)^{* * *}$ \\
\hline Constant & $0.07795(0.04193)^{*}$ \\
\hline
\end{tabular}

Note: $* *, * * *$ indicate significance at the 0.05 , and 0.01 levels, respectively. All findings are attained with xtscc codes in Stata, and robust standard errors are reported in parenthesis.

Driscoll and Kraay (1998) fixed effect findings are displayed in Table 4, based on heteroscedasticity, autocorrelation, and cross section dependence

DOI: $10.24818 / 18423264 / 54.3 .20 .10$ 
consistent estimators. It is seen that economic freedom has positive and significant impact on human development.

Table 5.Estimation Findings of CCE and AMG

\begin{tabular}{|c|c|}
\hline \multicolumn{2}{|c|}{ CCE Estimator } \\
\hline Variables & Model 1 \\
\hline Economic Freedom & $0.00096(0.00026)^{* * *}$ \\
\hline Trend & $-0.00031(0.00113)$ \\
\hline Constant & $-0.02114(0.10101)$ \\
\hline \multicolumn{2}{|c|}{ AMG Estimator } \\
\hline Economic Freedom & $0.00102(0.00019)^{* * *}$ \\
\hline Trend & $-0.00087(0.00935)$ \\
\hline Constant & $0.67264(0.01780)^{* * *}$ \\
\hline
\end{tabular}

Note: $* *, * * *$ indicate significance at the 0.05 , and 0.01 levels, respectively. All findings are attained with xtmg codes in Stata, and robust standard errors are reported in parenthesis.

CCE and AMG findings support the results of Driscoll and Kraay (1998) fixed effect in Table 5. Economic freedom has positive and significant impact on human development. One unit increase in economic freedom approximately increases human development by 0.001 in the long run for bivariate relationship.

Table 6.Cross Section Findings of AMG

\begin{tabular}{|c|c|c|c|}
\hline Countries & EFI & Trend & Constant \\
\hline Bulgaria & $\begin{array}{c}0.00083 \\
(0.00037)^{* * *}\end{array}$ & $\begin{array}{c}0.00501 \\
(0.00060)^{* * *}\end{array}$ & $\begin{array}{c}0.65842 \\
(0.01654)^{* * *}\end{array}$ \\
\hline Croatia & $\begin{array}{c}0.00090 \\
(0.00031)^{* * *}\end{array}$ & $\begin{array}{c}-0.00137 \\
(0.054)^{* *}\end{array}$ & $\begin{array}{c}0.67175 \\
(0.01552)^{* * *}\end{array}$ \\
\hline Czech R. & 0.00035 & -0.00006 & 0.74123 \\
& $(0.00042)$ & $(0.00068)$ & $(0.02942)^{* * *}$ \\
\hline Estonia & 0.00058 & 0.00005 & 0.70119 \\
& $(0.00033)^{*}$ & $(0.00062)$ & $(0.02308)^{* * *}$ \\
\hline Hungary & 0.00037 & -0.00069 & 0.72274 \\
& $(0.00025)$ & $(0.00037)^{*}$ & $(0.01463)^{* * *}$ \\
\hline Latvia & 0.00089 & -0.00553 & 0.62936 \\
& $(0.00029)^{* * *}$ & $(0.00053)^{* * *}$ & $(0.01797)^{* * *}$ \\
\hline Lithuania & 0.00139 & -0.00003 & 0.63962 \\
& $(0.00032)^{* * *}$ & $(0.00063)$ & $(0.01786)^{* * *}$ \\
\hline Poland & 0.00161 & 0.00109 & 0.66211 \\
& $(0.00036)^{* * *}$ & $(0.00074)$ & $(0.02156)^{* * *}$ \\
\hline
\end{tabular}


The Impact of Economic Freedom on Human Development in European Transition Economies

\begin{tabular}{|c|c|c|c|}
\hline Romania & $\begin{array}{c}0.00178 \\
(0.00047)^{* * *}\end{array}$ & $\begin{array}{c}-0.00297 \\
(0.00116)^{* *}\end{array}$ & $\begin{array}{c}0.59656 \\
(0.02253)^{* * *}\end{array}$ \\
\hline Slovakia & $\begin{array}{c}0.00210 \\
(0.00043)^{* * *}\end{array}$ & $\begin{array}{c}0.00769 \\
(0.00106)^{* * *}\end{array}$ & $\begin{array}{c}0.63391 \\
(0.02307)^{* * *}\end{array}$ \\
\hline Slovenia & $\begin{array}{c}0.00056 \\
(0.00031)^{*}\end{array}$ & $\begin{array}{c}-0.00273 \\
(0.00061)^{* * *}\end{array}$ & $\begin{array}{c}0.76260 \\
(0.01771)^{* * *}\end{array}$ \\
\hline
\end{tabular}

Note: $*, * *, * * *$ indicate significance at the $0.1,0.05$, and 0.01 levels, respectively. All findings are attained with xtmg codes in Stata, and robust standard errors are reported in parenthesis.

Cross section findings of each country are displayed in Table 6, leaning on AMG estimator. All estimations are done with constant and trend models. All cross section estimators are found significant, excluding Hungary and Czech Republic. Economic freedom affects positively and significantly human development relatively more in Poland, Romania, and Slovakia in the long run.

\subsection{Bootstrap Panel Causality Findings}

Table 8.Panel Causality Findings I

\begin{tabular}{|c|c|c|c|c|}
\hline \multicolumn{5}{|c|}{$\mathrm{H}_{0}$ : Economic Freedom does not cause Human Development } \\
\hline Countries & Wald & $\% 1$ & $\% 5$ & $\% 10$ \\
\hline Bulgaria & 2.141 & 16.031 & 9.893 & 7.558 \\
\hline Croatia & 0.825 & 16.300 & 8.441 & 5.671 \\
\hline Czech R. & $2.832^{*}$ & 6.823 & 3.711 & 2.607 \\
\hline Estonia & 3.910 & 14.329 & 8.397 & 5.863 \\
\hline Hungary & 0.350 & 30.512 & 17.436 & 12.843 \\
\hline Latvia & 0.168 & 14.097 & 7.076 & 4.849 \\
\hline Lithuania & 0.645 & 20.095 & 9.709 & 6.355 \\
\hline Poland & 0.191 & 24.306 & 14.146 & 10.457 \\
\hline Romania & $4.480^{*}$ & 11.373 & 5.977 & 4.101 \\
\hline Slovakia & $106.830^{* * *}$ & 71.361 & 47.720 & 38.479 \\
\hline Slovenia & 0.294 & 12.608 & 6.453 & 4.377 \\
\hline \multicolumn{5}{|c|}{ Cross Section Dependency Findings of Causality Model } \\
\hline Tests & LM1 & LM2 & CD & LM adj $^{*}$ \\
\hline Statistics & $911.736^{* * *}$ & $81.687 * * *$ & $30.063^{* * *}$ & $63.129^{* * *}$ \\
\hline
\end{tabular}

Note: $*, * * *$ indicate significance at the 0.1 , and 0.01 levels, respectively. Critical values are attained with 10.000 replications. All estimates are done with Gauss 10.

The strong and high correlation between HDI and EFI bring the question of causality between two. If countries have more economic freedom, this means more

DOI: $10.24818 / 18423264 / 54.3 .20 .10$ 
development. This increment in development may lead to more economic freedom further in the future (Gwartney et al., 1999). Bootstrap cross section causality findings running from economic freedom to human development takes place in Table 8. It is seen that there is significant findings of bootstrap Granger causality in Czech Republic, Romania, and Slovakia.

Table 9.Panel Causality Findings II

\begin{tabular}{|c|c|c|c|c|}
\hline \multicolumn{5}{|c|}{$\mathrm{H}_{0}$ : Human Development does not cause Economic Freedom } \\
\hline Countries & Wald & $\% 1$ & $\% 5$ & $\% 10$ \\
\hline Bulgaria & 5.156 & 56.073 & 40.685 & 34.902 \\
\hline Croatia & 8.737 & 41.53 & 29.685 & 24.591 \\
\hline Czech R. & 4.669 & 11.836 & 8.39 & 6.881 \\
\hline Estonia & 0.689 & 15.317 & 9.268 & 7.132 \\
\hline Hungary & 2.453 & 26.316 & 17.091 & 13.524 \\
\hline Latvia & 1.108 & 24.885 & 16.135 & 13.058 \\
\hline Lithuania & 8.773 & 31.933 & 22.533 & 18.745 \\
\hline Poland & 0.793 & 21.836 & 14.845 & 12.109 \\
\hline Romania & 20.688 & 52.931 & 39.758 & 33.984 \\
\hline Slovakia & 0.049 & 30.594 & 21.618 & 17.721 \\
\hline Slovenia & $5.507 *$ & 13.242 & 7.452 & 5.273 \\
\hline \multicolumn{5}{|c|}{ Cross Section Dependency Findings of Causality Model } \\
\hline Tests & LM1 & LM2 & CD & LM $_{\text {adj }}$ \\
\hline Statistics & $179.500^{* * *}$ & $11.871 * * *$ & -0.922 & $63.046^{* * *}$ \\
\hline
\end{tabular}

Note: *, *** indicate significance at the 0.1 , and 0.01 levels, respectively. Critical values are attained with 10.000 replications. All estimates are done with Gauss 10.

Bootstrap cross section causality findings running from human development to economic freedom are displayed in Table 9. It is seen that there is significant unidirectional Granger Causality just in Slovenia. Meanwhile, whole panel causality findings also reveal that there is significant unidirectional bootstrap causality running from economic freedom to human development with $31.410^{*}$ Panel Fisher value, whereas Panel Fisher value of causality findings from human development to economic freedom is 11.767 leaning on whole panel findings.

Bootstrap cross section significant findings running from economic freedom sub-indices to human development are taken place in Appendix 1. According to findings, there is evidence for unidirectional causality running from property rights (PR) to human development in Croatia, Latvia, and Romania. While there is unidirectional causality running from government integrity (GI) to HDI just in Poland, there is unidirectional causality from business freedom (BF) to HDI just in Estonia. Meanwhile, there is evidence of unidirectional causality from monetary 
The Impact of Economic Freedom on Human Development in European Transition Economies

freedom (MF) to HDI in Lithuania and Romania, whereas from trade freedom (TF) to HDI in Latvia, Lithuania, and Slovakia.

Bootstrap cross section significant findings running from human development to economic freedom sub-indices are taken place in Appendix 1 as well. According to findings, there is significant evidence running from HDI to GI in Slovakia, whereas from HDI to government spending (GS) in Slovenia. There is bidirectional causality between tax burden (TB) and HDI just in Slovenia. Moreover, there is unidirectional causality from HDI to TB in Bulgaria, Estonia, and Slovakia. There is unidirectional causality running from HDI to BF in Slovenia, Czech Republic, Lithuania; from HDI to MF in Czech Republic, and Latvia; and from HDI to TF just in Romania.

\section{Conclusions}

The objective of this study was to investigate the bivariate relationship between human development and economic freedom index for 11 European Transition Economies for the period spanning from 1996-2018. First of all, cross section dependency situation of units was examined, and unit root structure was analyzed by taking cross section dependency into consideration. It has been seen that there is unit root in level, and both are stationary in their first differences. At the second step, bivariate cointegration relationship has been brought out based on heterogeneity situation of the panel structure considering cross section dependency. After that, cointegration model has been estimated by CCE, AMG, and Driscoll and Kraay (1998) fixed effect estimators, which revealed similar findings as a whole. One unit increment in economic freedom approximately increases human development by 0.001 . So, more freedom means more development for these countries in accordance with Goldsmith (1997) study. Besides, economic freedom affects positively and significantly human development relatively high in Poland, Romania, and Slovakia in the long run according to AMG cross section findings.

High correlation between human development and economic freedom brought the interrogation of causality relationship. It has been emerged that there is unidirectional causality running from economic freedom to human development based on Konya (2006) bootstrap panel causality in whole panel. According to cross section bootstrap Granger causality, there is evidence of one-way causality operating from economic freedom to human development in Czech Republic, Romania, and Slovakia, whilst there is evidence of one-way causality operating form human development to economic freedom just in Slovenia. As for the subindices of the economic freedom index, there is a one-way causality from private rights and monetary freedom to HDI in Romania, while in Slovakia there is a oneway causality from trade freedom to HDI and from government integrity to human development in Poland. Moreover, there is reciprocal two-way Granger causality between tax burden and human development in Slovenia. As a result, all findings imply that economic freedom is a crucial factor of development in CEE countries.

DOI: $10.24818 / 18423264 / 54.3 .20 .10$ 


\section{REFERENCES}

[1] Acikgoz, B., Amoah, A., Yılmazer, M. (2016), Economic Freedom and Growth: A Panel Cointegration Approach. Panoeconomicus, 63(5):541-562; [2] Bahtiyar, E., Karabacak, M. (2018), Economic Freedom and Human Development: A Panel Causality Test on Selected Countries. The Seventh International Conference in Economics, 23-25 January,Lisbon: Econworld; [3] Bai, J., Ng, S. (2004), A Panic Attack on Unit Roots and Cointegration. Econometrica, 72(4): 1127-1177;

[4] Breush, T. S., Pagan, A. R. (1980), The Lagrange Multiplier Test and its Application to Model Specification in Econometrics. The Review of Economic Studies, 27(2):19-32;

[5] Dawson, J. W. (2003),Causality in the Freedom-Growth Relationship. European Journal of Political Economy, 19, 479-495;

[6] De Haan, J., Siermann, C.L.J. (1998),Further Evidence on the Relationship between Economic Freedom and Economic Growth. Public Choice, 95,363-380; [7] Driscoll, J. C., Kraay, A. C. (1998), Consistent Covariance Matrix Estimation with Spatially Dependent Panel Data. Review of Economics and Statistics, 80(4): 549-560;

[8] Eberdhardt, M, Bond, S. (2009),Cross-Section Dependence in Nonstationary Panel Models: A Novel Estimator. MPRA Working Paper 17692;

[9] Esposito, A., Zaleski, P. A. (1999),Economic Freedom and the Quality of Life: An Empirical Analysis. Constitutional Political Economy, 10, 185-197; [10] Farr, W.K., Lord, R.A., Wolfenbarger, J.L. (1998),Economic Freedom, Political Freedom, and Economic Well-Being: A Causality Analysis. Cato Journal, 18(2): 247-262;

[11] Goldsmith, A. A. (2017),Economic Rights and Government in Developing Countries: Cross-National Evidence on Growth and Development. Studies in Comparative International Development, 32(2): 29-44;

[12] Graafland, J. (2019),Contingencies in the Relationship between Economic Freedom and Human Development: The Role of Generalized Trust. Journal of Institutional Economics, 1-16;

[13] Guloglu, B., Ivrendi, M. (2008), Output Fluctuations: Transitory or Permanent? The Case of Latin America. Applied Economics Letters, 17(4): 381386;

[14] Guney, T. (1997),Economic Freedom and Human Development. Hitit University Journal of Social Science Institute, 10(2): 1109-1120;

[15] Gwartney, J. D., Lawson, R. A., Holcombe, R. G. (1999), Economic Freedom and the Environment for Economic Growth. Journal of Institutional and Theoretical Economics, 155(4): 643-663;

[16] Heckelman, J.C. (2000),Economic Freedom and Economic Growth: A Short-Run Causal Investigation. Journal of Applied Economics, 3(1): 71-91; 
The Impact of Economic Freedom on Human Development in European Transition Economies

[17] Kar, M., Nazlığglu, Ş., Ağır, H. (2011),Financial Development and Economic Growth Nexus in the MENA Countries: Bootstrap Panel Granger Causality Analysis. Economic Modelling, 28, 685-693;

[18] Menyah, K., Nazlığlu, Ş., Wolde-Rufael, Y. (2014),Financial Development, Trade Openness and Economic Growth in African Countries: New Insights from a Panel Causality Approach. Economic Modelling, 37, 386-394; [19] Konya, L. (2006), Exports and Growth: Granger Causality Analysis on OECD Countries with a Panel Data Approach. Economic Modelling, 23, 978992;

[20] Panahi, H., Assadzadeh, A., Rafaei, R. (2014),Economic Freedom and Economic Growth in MENA Countries. Asian Economic and Financial Review, 4(1): 105-116;

[21] Pesaran, M. H. (2004), General Diagnostic Tests for Cross Section Dependence in Panels. CESifo Working Paper 1229, IZA Discussion Paper 1240; [22] Pesaran, M. H. (2006), Estimation and Inference in Large Heterogeneous Panels with a Multifactor Error Structure. Econometrica, 74(4): 967-1012; [23]Pesaran, M. H. (2007), A Simple Panel Unit Root Test in the Presence of Cross-Section Dependence. Journal of Applied Econometrics, 22, 265-312;

[24]Pesaran, M. H., Ullah, A., Yamagata, T. (2008),A Bias-Adjusted LM Test of Error Cross-Section Independence. Econometrics Journal, 11, 105-127;

[25]Pesaran, M. H., Yamagata, T. (2008),Testing Homogeneity in Large Panels. Journal of Econometrics, 142, 50-93;

[26] Piatek, D., Szarzec, K., Pilc, M. (2013),Economic Freedom, Democracy and Economic Growth: A Causal Investigation in Transition Countries. PostCommunist Economies, 25(3): 267-288;

[27] Ram, R. (2014),Measuring Economic Freedom: A Comparison Major Sources. Applied Economics Letters, 21(12): 852-856;

[28] Sen, A. (1993),The Economics of Life and Death. Scientific American, 208(5): 40-47;

[29] Smith, A. (1776),An Inquiry into the Nature and Causes of the Wealth of Nations. Cannan, E., Ed., London: Methuen, 1904, available at: https://oll.libertyfund.org/titles/237, last accessed 12.09.2019;

[30] The Heritage Foundation (2019),Index of Economic Freedom. Available at: https://www.heritage.org/index/explore? view $=$ by-region-country-year \& $u=637$ 119903210952288, last accessed 16.12.2019;

[31] UNDP (2010), The Real Wealth of Nations: Pathways to Human

Development. United Nations Development Programme Human Development Report, $20^{\text {th }}$ Anniversary Edition;

[32] UNDP (2019),Human Development Data 1990-2018. United Nations

Development Programme, available at: http://hdr.undp.org/en/data\#, last accessed 27.01.2020;

[33] Westerlund, J. (2008),Panel Cointegration Tests of the Fisher Effect. Journal of Applied Econometrics, 23, 193-233;

DOI: 10.24818/18423264/54.3.20.10 
[34] Wooldridge, J. M. (2013),Introductory Econometrics: A Modern Approach. $5^{\text {th }}$ edition, Ohio: South-Western Cengage Learning.

Appendix 1.Panel Causality Findings of Sub-indices of Economic Freedom $\mathrm{H}_{0}$ : Economic Freedom sub-indices does not cause Human Development

\begin{tabular}{|c|c|c|c|c|c|}
\hline Causality & Countries & Wald & $\% 1$ & $\% 5$ & $\% 10$ \\
\hline \multirow{3}{*}{ PR->HDI } & Croatia & $35.110^{* * *}$ & 22.692 & 10.431 & 7.882 \\
\cline { 2 - 6 } & Latvia & $9.840^{*}$ & 22.472 & 13.052 & 9.801 \\
\cline { 2 - 6 } & Romania & $26.115^{*}$ & 45.015 & 30.414 & 23.921 \\
\hline GI->HDI & Poland & $6.728^{* *}$ & 8.230 & 5.718 & 4.686 \\
\hline TB->HDI & Slovenia & $13.553^{* * *}$ & 10.855 & 5.257 & 3.576 \\
\hline BF->HDI & Estonia & $24.270^{* *}$ & 27.175 & 17.146 & 13.283 \\
\hline MF->HDI & Lithuania & $2.628^{* *}$ & 2.970 & 1.639 & 1.143 \\
\cline { 2 - 6 } & Romania & $83.998^{* * *}$ & 58.550 & 35.610 & 28.868 \\
\hline \multirow{3}{*}{ TF->HDI } & Latvia & $18.960^{*}$ & 30.333 & 19.946 & 16.380 \\
\cline { 2 - 6 } & Lithuania & $29.475^{* * *}$ & 25.381 & 16.333 & 13.062 \\
\cline { 2 - 6 } & Slovakia & $51.974 *$ & 83.206 & 55.187 & 44.940 \\
\hline
\end{tabular}

$\mathrm{H}_{0}$ : Human Development does not cause Economic Freedom sub-indices

\begin{tabular}{|c|c|c|c|c|c|}
\hline HDI->GI & Slovakia & $12.953 * * *$ & 8.944 & 4.735 & 3.192 \\
\hline \multirow{3}{*}{ HDI-> TB } & Bulgaria & $11.560 * * *$ & 9.319 & 4.690 & 3.125 \\
\cline { 2 - 6 } & Estonia & $12.564 * * *$ & 9.610 & 5.028 & 3.352 \\
\cline { 2 - 6 } & Slovakia & $98.949 * * *$ & 72.657 & 48.046 & 38.815 \\
\cline { 2 - 6 } & Slovenia & $20.975 * *$ & 26.586 & 10.616 & 6.760 \\
\hline HDI->GS & Slovenia & $18.094 * * *$ & 9.248 & 4.908 & 3.231 \\
\hline HDI->BF & Czech R. & $22.371 * * *$ & 18.567 & 9.583 & 6.545 \\
\cline { 2 - 6 } & Lithuania & $11.572 * *$ & 13.032 & 6.061 & 3.926 \\
\hline \multirow{2}{*}{ HDI->MF } & Czech R. & $4.956 *$ & 12.203 & 6.441 & 4.378 \\
\cline { 2 - 6 } & Latvia & $34.187 * * *$ & 28.722 & 18.090 & 13.991 \\
\hline HDI->TF & Romania & $7.568 *$ & 15.944 & 7.771 & 5.060 \\
\hline
\end{tabular}

Note: *,**,*** indicate significance at the $0.1,0.05$, and 0.01 levels, respectively. Critical values are attained with 10.000 replications. All estimates are done with Gauss 10. Non-significant findings are omitted to benefit from space, and available if demanded. 